KRZYSZTOF OŻÓG

Uniwersytet Jagielloński, Kraków

\title{
UWAGI O BADANIACH NAD ŚREDNIOWIECZNĄ KULTURĄ UMYSŁOWĄ EUROPY ŚRODKOWO-WSCHODNIEJ
}

Dyskusja nad koncepcją Europy Środkowo-Wschodniej tocząca się w historiografii od kilkudziesięciu lat, sprzyjała rozwojowi badań nad dziejami tego regionu Europy i próbom określenia jego granic geograficzno-historycznych, specyfiki, głównych nurtów przemian, powiązań z innymi obszarami europejskimi i kręgami cywilizacyjnymi ${ }^{1}$. Ta długotrwała debata zaowocowała również kilkoma zarysami integralnej historii Europy Środkowo-Wschodniej od jej narodzin w X-XI w. do czasów współczesnych, a także ujęciami jej dziejów w okresie średniowiecza ${ }^{2}$. W znacznej mierze pod wpływem Oskara Haleckiego, Jerzego Kłoczowskiego i Jenő Szűcsa utrwalił się pogląd, że w okresie wieków średnich Europę Środkowo-Wschodnią stanowiły trzy monarchie: polska, czeska i węgierska rządzone przez dynastie Piastów, Przemyślidów i Arpadów oraz ich sukcesorów Andegawenów, Luksemburgów, Jagiellonów

${ }^{1} \mathrm{Na}$ temat dyskusji zob. J. Kłoczowski, Europa Środkowowschodnia w historiografii krajów regionu, Lublin 1993; idem, Europa Środkowowschodnia w przestrzeni europejskiej, w: Europa Środkowowschodnia od X do XVIII wieku - jedność czy różnorodność?, red. K. Baczkowski, J. Smołucha, Kraków 2005, s. 9-23; M. Borgolte, Ostmitteleuropa aus der Sicht des Westens, w: Ostmitteleuropa im 14.-17.Jahrhundert - eine Region oder Region der Regionen?, red. M. Dygo, S. Gawlas, H. Grala, Warszawa 2003, s. 5-19.

${ }^{2}$ Tłumaczenie polskie: P. Wandycz, Cena wolności. Historia Europy Środkowo-Wschodniej od średniowiecza do współczesności, Kraków 1995 (oryg. ang. 1992); G. Castellan, Histoire des peuples d'Europe Centrale, Paris 1994; Historia Europy Środkowo-Wschodniej, t. 1-2, red. J. Kłoczowski, Lublin 2000; J. W. Sedlar, East Central Europe in the Middle Ages, 1000-1500, Seattle-London 1994, A History of East Central Europe, t. 3; L. R. Johnson, Central Europe. Enemies, Neighbors, Friends, New York-London 1996; J. Kłoczowski, Młodsza Europa. Europa Środkowo-Wschodnia w kręgu cywilizacji chrześcijańskiej średniowiecza, Warszawa 1998. 
i Habsburgów, a także władztwo zakonu krzyżackiego nad Bałtykiem i Litwa po przyjęciu chrześcijaństwa ${ }^{3}$.

Na grunt badań nad średniowieczną kulturą umysłową koncept Europy Środkowo-Wschodniej był wprowadzany różnymi drogami. Najpierw pojawił się on w odniesieniu do fundacji uniwersytetów w XIV w. w Pradze, Krakowie, Wiedniu i Peczu w czasie międzynarodowej konferencji z okazji sześćsetlecia powstania Uniwersytetu Krakowskiego w maju 1964 r., zorganizowanej przy współudziale Commission Internationale pour l'Histoire des Universités pod przewodnictwem Svena Stellinga-Michauda. Pierwsza jej część, zatytułowana: „Les premières universités de l'Europe centrale au moyen âge", była poświęcona założeniu wyżej wspomnianych uniwersytetów (wystąpienia Zofii Kozłowskiej-Budkowej, Františka Kavki, Endre Kovácsa i Franza Galla) ${ }^{4}$. W trakcie dyskusji Adam Vetulani na podstawie aktów fundacyjnych trzech uniwersytetów: krakowskiego, wiedeńskiego i peczańskiego stwierdził wiele wspólnych cech odnoszących się do procesu ich fundacji i organizacji. Wskazywał również na rolę Uniwersytetu Praskiego i jego założyciela Karola IV Luksemburga,którego starali się naśladować Kazimierz Wielki, Rudolf IV i Ludwik Andegaweński. Krakowski badacz podkreślał pewną specyfikę uniwersytetów środkowoeuropejskich w stosunku do uniwersytetów francuskich i włoskich ${ }^{5}$. A. Vetulani oraz inni uczestnicy dyskusji, m.in. Aleksander Gieysztor, używali pojęcia „L'Europe Centrale”(„Europa Środkowa”) na określenie obszaru, na którym powstały

${ }^{3}$ O. Halecki, Historia Europy - jej granice i podziały, Lublin 1994 (oryg. ang. 1950), s. 147-166; J. Szűcs, Trzy Europy, Lublin 1995 (tł. z wyd. franc. 1985, oryg. węg. 1981), s. 29-110; J. Kłoczowski, Młodsza Europa, s. 11 i nn.; idem, Wprowadzenie, w: Historia Europy Środkowo-Wschodniej, t. 1, s. 7-20; Ch. Lübke, Mitteleuropa, Ostmitteleuropa, östliches Europa: Wahrnehmung und frühe Strukturen eines Raumes, w: Die „Blüte” der Staaten des östlichen Europa im 14. Jahrhundert, red. M. Löwener, Wiesbaden 2004, s. 14-42; A. Adamska, M. Mostert, Preface, w: The Development of Literate Mentalities in East Central Europe, red. iidem, Turnhout 2004, s. 1-6; P. Górecki, N. van Deusen, Toward a New Cultural History of East Central Europe?, w: Central and Eastern Europe in the Middle Ages. A Cultural History, red. iidem, London-New York 2009, s. 205-212; East-Central Europe in European History. Themes and Debates, red. J. Kłoczowski, H. Łaszkiewicz, Lublin 2009.

${ }^{4}$ Les Universités Européennes du XIVe au XVIII siècle. Aspects et problèmes. Actes du Colloque International à l'occasion du VIe Centenaire de L'Université Jagellonne de Cracovie 6-8 Mai 1964, red. S. Stelling-Michaud, Genève 1967, s. 13-68; Z. Kozłowska-Budkowa, La fondation de l'Université de Cracovie, en 1364, et son rôle dans le développement de la civilisation en Pologne, w: Les Universités Européennes, s. 13-25; F. Kavka, Die Gründung der Universität in Prag und ihre Bedeutung für die Entwicklung der tschechischen Kultur, w: Les Universités Européennes, s. 26-35; E. Kovács, Die Gründung der Universität Pécs und ihre Bedeutung für die Ungarische Kultur, w: Les Universités Européennes, s. 36-47; F. Gall, Gründung und Anfänge der Wiener Universität, w: Les Universités Européennes, s. 48-55.

${ }^{5}$ Discussion de la première partie: A. Vetulani, Cracovie, Vienne et Pécs: trois fondations universitaires, w: Les Universités Européennes, s. 56-59. 
uniwersytety w Pradze, Krakowie, Wiedniu i Peczu, tj. Czech, Polski, Austrii i Węgier, ale nie nawiązywali bezpośrednio do koncepcji Europy Środkowo-Wschodniej O. Haleckiego ${ }^{6}$.

W następnych latach A. Vetulani przeprowadził systematyczne badania porównawcze nad fundacjami uniwersyteckimi monarchów środkowoeuropejskich i ich rezultaty opublikował w szeregu artykułach ${ }^{7}$, a przede wszystkim w książce pt. Początki najstarszych wszechnic środkowoeuropejskich. Zasługuje ona na baczną uwage, ponieważ jej autor, co prawda bez szerszego uzasadnienia koncepcyjnego i metodologicznego, dokonał zwięzłego, komparatystycznego omówienia przemian politycznych i kulturalnych w Czechach, Polsce i na Węgrzech od narodzin tych trzech monarchii do połowy XIV w. Wskazał przy tym na szczególnie bliskie związki tych państw i liczne podobieństwa w zakresie rozwoju struktur kościelnych i środowisk kultury intelektualnej, a także relacje z Europą Zachodnią. Konsekwentnie uzasadniał historyczną odrębność Europy Środkowej kształtującą się od $\mathrm{X}$ w. nie tylko na poziomie politycznych i kościelnych struktur tych trzech monarchii, ale również w sferze kultury umysłowej. Nieco bardziej szczegółowej analizie krakowski uczony poddał studia osób pochodzących z Czech, Polski i Węgier w uniwersytetach włoskich (głównie Bolonii i Padwie), podkreślając, że od schyłku XII w. rosła ich liczba, przyczyniając się do „pogłębienia kultury umysłowej społeczeństw środkowoeuropejskich" w XIII i pierwszej połowie XIV w. To zaś doprowadziło monarchów i elitę w każdym z tych krajów do myśli o potrzebie fundacji uniwersytetu ${ }^{8}$. Następnie A. Vetulani omówił po kolei procesy fundacyjne uniwersytetów: praskiego, krakowskiego, wiedeńskiego i peczańskiego oraz rolę władców i papiestwa w powstaniu tych uczelni'. Na drodze szczegółowej analizy suplik kierowanych do Stolicy Apostolskiej, bulli papieskich i dokumentów fundacyjnych

${ }^{6}$ Discussion de la première partie, w: Les Universités Européennes, s. 56-68.

${ }^{7}$ A. Vetulani, La fondation des universités dans L'Europe Centrale aux temps du pontificat d'Urbain V, w: La Storia del diritto nel quadro delle scienze storiche. Atti del primo Congresso internazionale della Società Italiana di Storia del Diritto, Firenze 1966, s. 361-367; idem, Urban $V$ wobec nowo zakładanych uniwersytetów środkowoeuropejskich, w: Pastori et magistro, red. A. Krupa i in., Lublin 1966, s. 203-228; idem, Les origines de l'Université de Cracovie, APH 1966, 13, s. 14-40; idem, Modus procedendi bei der Gründung der Universitäten im Zeitalter des Ponifikats Urban V., w: Acta Facultatis juridicae Universitatis Comenianae. Die juristische Bildung in der Slovakei und Ungarn bis 1848, red. M. Vietor, Bratislava 1968, s. 311-318; idem, Die Universitätspolitik Papst Urban V., w: Ius Sacrum. Klaus Mörsdorf zum 60. Geburtstag, red. A. Scheurmann, G. May, München 1969, s. 292-209; idem, Les origines et le sort des universités de l'Europe centrale et orientale fondées au cours du XIVe siècle, w: The Universities in the Late Middle Ages, red. J. Ijsewijn, J. Paquet, Leuven 1978, s. $148-167$.

${ }^{8}$ Idem, Poczatki najstarszych wszechnic środkowoeuropejskich, Wrocław 1970, s. 8-32.

${ }^{9}$ Ibidem, s. 55-175. 
wspomniany badacz ustalił liczne podobieństwa w trybie załatwiania suplik monarszych w Awinionie, a także w zapisach dokumentów fundacyjnych Kazimierza Wielkiego dla krakowskiej wszechnicy i Rudolfa IV dla wiedeńskiej (nie zachował się taki dokument Ludwika Andegaweńskiego dla uniwersytetu w Peczu) oraz decyzjach papieskich o zakazie utworzenia fakultetów teologii w tych trzech uczelniach. Wskazał także na istotne paralele w trudnościach, z jakimi przyszło się zmagać powstającym uniwersytetom w Krakowie, Wiedniu i Peczu. Na uwagę zasługuje również szeroki kontekst historyczny, w jakim A. Vetulani umieścił fundacje uniwersyteckie Karola IV, Kazimierza Wielkiego, Rudolfa IV i Ludwika Andegaweńskiego, gdyż w znacznej mierze uwzględniał sytuację polityczną i społeczną w państwach środkowoeuropejskich oraz poziom ich kultury umysłowej i stan szkolnictwa w miastach, w których tworzono uczelnie. Omawiana praca inspirowała w następnych dziesięcioleciach polskie badania nad początkami krakowskiej wszechnicy w kontekście fundacji uniwersyteckich w Pradze, Wiedniu i Peczu ${ }^{10}$. W mniejszym stopniu ustalenia krakowskiego uczonego oddziałały na historiografię poza Polską ${ }^{11}$.

Na gruncie niemieckim problemem kształtowania się sieci uniwersytetów w Europie Środkowej od połowy XIV do drugiej dekady XV w. zajął się Ferdinand Seibt, jeden z protagonistów koncepcji Westmitteleuropa-Ostmitteleuropa $\mathrm{w}$ historiografii niemieckiej ${ }^{12}$. Wszystkie uniwersytety powstałe wówczas na terytorium Rzeszy Niemieckiej, poczynając od Pragi, a na Rostocku kończąc, wraz z uczelnią w Krakowie i Peczu zaliczył do Europy Środkowej. Natomiast trzy królestwa: czeskie, polskie i węgierskie, znajdujące się pod panowaniem Karola IV Luksemburga, Kazimierza Wielkiego i Ludwika Andegaweńskiego uważał za przynależne do Europy Środkowo-Wschodniej („Ostmitteleuropa”) i mające wiele cech wspólnych w sferze organizacji i ideologii państwowej ${ }^{13}$. Domyślnie uniwersytety w Pradze, Krakowie i Peczu zostały przezeń w pewien sposób wy-

10 Por. A. Partyka, Papieskie zatwierdzenia fundacji uniwersytetów środkowoeuropejskich w latach 1347-1386, „Analecta Cracoviensia” 9, 1977, s. 9-27; L'Université et la ville au Moyen Age et d'autres questions du passé universitaire, red. J. Wyrozumski, Kraków 1993; J. Wyrozumski, Z najstarszych dziejów Uniwersytetu Krakowskiego. Szkice, Kraków 1996, s. 21-33; S. Szczur, Papież Urban V i powstanie uniwersytetu w Krakowie w 1364 r., Kraków 1999; K. Stopka, Głos w dyskusji nad fundacja uniwersytetu w Krakowie, „Rocznik Krakowski" 71, 2005, s. 31-40.

${ }^{11}$ Zob. P.W. Knoll, Casimir the Great and the University of Cracow, ,Jahrbücher für Geschichte Osteuropas", Neue Folge 16, 1968, s. 232-249.

${ }^{12}$ F. Seibt, Von Prag bis Rostock. Zur Gründung der Universitäten in Mitteleuropa, w: Festschrift für Walter Schelsinger, red. H. Beumann, Köln-Wien 1973, s. 407-426; por. Westmitteleuropa. Ostmitteleuropa. Vergleiche und Beziehungen. Festschrift für Ferdinand Seibt zum 65. Geburtstag, red. W. Eberhard i in., München 1992.

${ }^{13}$ F. Seibt, op. cit., s. 409-410. 
dzielone z Europy Środkowej. W swoim studium F. Seibt zaprezentował w syntetycznym ujęciu proces fundacji 12 uniwersytetów, określając główne czynniki tak dynamicznego rozwoju sieci uniwersyteckiej. Przede wszystkim wskazał na ambicje władców terytorialnych dążących do posiadania wszechnicy w swoich państwach. Zanalizował ustrój i struktury wewnętrzne wspomnianych uniwersytetów (władza rektora, wydziały, nacje, system kolegialny) i zastosowane wzorce organizacyjne. Przekonująco dowodził, że Uniwersytet Praski wywarł wielki wpływ na charakter fundacji uniwersyteckich w Europie Środkowej, albowiem nie tylko jego mistrzowie i studenci poprzez migracje przyczyniali się do tworzenia nowych uczelni, ale również z Pragi przejmowano rozwiązania ustrojowe co do nacji, fakultetów i kolegiów. Niemiecki badacz wręcz sformułował tezę o „praskim typie uniwersytetu” w Europie Środkowej w okresie średniowiecza ${ }^{14}$. Wypada zaznaczyć, że F. Seibt w swoich analizach dotyczących uniwersytetów w Pradze, Krakowie, Wiedniu i Peczu nie odwoływał się do prac A. Vetulaniego.

W polskiej mediewistyce przełomowe znaczenie dla badań nad kulturą intelektualną Europy Środkowo-Wschodniej miały prace J. Kłoczowskiego, publikowane od początku lat siedemdziesiątych ubiegłego

${ }^{14}$ Ibidem, s. 426: „Nach diesem Überblick mag man geneigt sein, von einem Prager Typus in der frühen Geschichte der Universität in Mitteleuropa zu sprechen". Niejako kontynuacją badań F. Seibta stała się obszerna rozprawa F. Rexrotha (Deutsche Universitätsstiftungen von Prag bis Köln. Die Intentionen des Stifters und die Wege und Chancen ihrer Verwirklichung im spätmittelalterlichen deutschen Territorialstaat, Köln-Weimar-Wien 1992), który zrezygnował z pojęcia „Europa Środkowa”, a posługiwał się terminami „die deutschen Universitäten”, , ,der deutsche Territorialstaat”, ograniczając się do Rzeszy Niemieckiej. Szczegółowo zajął się więc powstaniem uniwersytetów w Pradze, Wiedniu, Chełmnie, Heidelbergu i Kolonii, rezygnując z objęcia analizą fundacji uczelni w Krakowie i Peczu. Niemiecki mediewista skrupulatnie zbadał akty fundacyjne wymienionych pięciu uniwersytetów, ukazując okoliczności i warunki ich utworzenia, aspiracje i cele fundatorów (władców, zakonu krzyżackiego i miasta Kolonii) oraz stosunek społeczeństw do zakładanych uczelni. W nieco odmienny sposób dziejami fundacji Uniwersytetu Krakowskiego w roku 1364 i 1400 zajął się Peter Moraw (Die hohe Schule in Krakau und das europäische Universitätssystem um 1400, w: Studien zum 15. Jahrhundert. Festschrift für Erich Meuten, red. J. Helmrath, H. Müller, współpr. H. Wolff, t. 1, München 1994, s. 521-539). Starał się on osadzić początkowy okres funkcjonowania wszechnicy do roku 1432 w kontekście uniwersytetów europejskich przełomu XIV i XV w., przede wszystkim uczelni w Rzeszy Niemieckiej. Ponieważ nie wykorzystał wielu szczegółowych ustaleń polskich mediewistów, nakreślił niepełny i mocno zniekształcony obraz początków krakowskiej wszechnicy. Z kolei analizę porównawczą systemu kolegialnego w uniwersytetach: praskim, wiedeńskim i heidelberskim przeprowadził Wolfgang E. Wagner (Universität und Kollegium in Prag, Wien und Heidelberg. Eine vergleichende Untersuchung spätmittelalterlicher Stiftungen im Spannungsfeld von Herrschaft und Genossenschaft, Berlin 1999), lecz nie odwoływał się do konceptu Europy Środkowej. 
wieku, w których programowo stosował do analizy zjawisk i procesów historycznych metodę porównawczą ${ }^{15}$. 0 jej zaletach i możliwościach napisał w 1976 r. w artykule pt. O historię porównawcza społeczeństw europejskich $^{16}$. Stopniowo dookreślał też koncepcję Europy Środkowo-Wschodniej, uznając za jej podstawowe jądro cztery państwa: czeskie, polskie (z Litwą od momentu zawarcia unii w 1386 r.), węgierskie i zakonu krzyżackiego. Niekiedy jednak znacznie poszerzał jej rozumienie, włączając w pole obserwacji historycznych dotyczących np. studiów uniwersyteckich monarchie skandynawskie. W panoramie średniowiecznych dziejów tej części Europy konsekwentnie umieszczał on analizy porównawcze szkolnictwa (parafialnego, kapitulnego, zakonnego) w Czechach, Polsce i na Węgrzech oraz uniwersytetów i studiów uniwersyteckich osób z tych monarchii, a także uwagi o elitach intelektualnych (w tym również humanistach) i ich twórczości. Najpełniej zaprezentował obraz średniowiecznej kultury intelektualnej Europy Środkowo-Wschodniej w dziełach: Europa słowiańska i Młodsza Euro$p a^{17}$. Stosowana przez J. Kłoczowskiego metoda komparatystyczna przyniosła interesujące wyniki ukazujące dynamikę rozwoju szkolnictwa parafialnego, jednego z podstawowych wyznaczników poziomu alfabetyzacji społeczeństw polskiego, czeskiego i węgierskiego ${ }^{18}$. Fundamentalne zna-

${ }^{15}$ J. Kłoczowski, Rozwój środkowowschodniej Europy w XIV wieku, w: Sztuka i ideologia XIV wieku. Materiały Sympozjum Komitetu Nauk o Sztuce Polskiej Akademii Nauk Warszawa, 29 i 30 listopada 1973 r., red. P. Skubiszewski, Warszawa 1975, s. 13-52; idem, Rozwój środkowowschodniej Europy w XV wieku, w: Sztuka i ideologia XV wieku. Materiały Sympozjum Komitetu Nauk o Sztuce polskie Akademii Nauk Warszawa, 1-4 grudnia 1976 r., red. P. Skubiszewski, Warszawa 1978, s. 17-53; idem, Le développement de la civilisation en Europe Centrale et Orientale au XIVe et XVe siècles, „Quaestiones Medii Aevi” 1, 1977, s. 111-138; idem, Europa słowiańska w XIV-XV wieku, Warszawa 1984. Równolegle do prac J. Kłoczowskiego studia porównawcze nad czterema monarchiami stanowymi XV-XVI w.: Polską, Litwą, Czechami i Węgrami, tworzącymi Europę Środkowo-Wschodnią, prowadził Stanisław Russocki. Koncentrował się jednak na ustroju politycznym, strukturach władzy i siłach politycznych (monarchia i stany) oraz doktrynach politycznych, nie zajmował się zaś zagadnieniami kultury umysłowej i elit intelektualnych. Zob. S. Russocki, Monarchie stanowe Środkowo-Wschodniej Europy XV-XVI wieku, KH 84, 1977, 1, s. 73-92; idem, Poczatki zgromadzeń stanowych $w$ Europie Środkowej, PH 66, 1975, 2, s. 171-188; idem, Les assemblées prérepresentatives en Europe Centrale. Préliminaires d'une analyse comparative, APH 1974, 30, s. 33-52; idem, The Parliamentary System in the $15^{\text {th }}$ Century in Central Europe, w: Poland in the $14^{\text {th }}$ International Congress of Historical Sciences in San Francisco, red. B. Geremek, A. Mączak, Wrocław 1975, s. 7-21; idem, Les structures politiques dans l'Europe des Jagellons, APH 1979, 39, s. 101-142; idem, Historia porównawcza a kultura. Elementy wspólnoty ustrojowo-prawnej Europy Środkowej w XV-XVI wieku, „Przegląd Humanistyczny" 29, 1985, 11/12, s. 21-27.

${ }^{16} \mathrm{~J}$. Kłoczowski, O historię porównawczą społeczeństw europejskich. Struktury społeczne, polityczne i kulturalne Europy XIII w., PH 67, 1976, 4, s. 527-535.

${ }^{17}$ Idem, Europa słowiańska, s. 196-237; idem, Młodsza Europa, s. 339-390.

${ }^{18}$ Idem, Młodsza Europa, s. 249-257, 342-346. 
czenie mają jego badania dotyczące procesu kształtowania się struktur szkolnictwa zakonnego mendykantów, szczególnie dominikanów i franciszkanów, oraz jego funkcji w zakresie formacji filozoficzno-teologicznej i duchowej zakonników. Uzupełniają one w istotny sposób obraz kultury scholastycznej w Europie Środkowo-Wschodniej ${ }^{19}$. Do najważniejszych konstatacji J. Kłoczowskiego należy stwierdzenie o wielkim skoku w rozwoju kultury szkolnej między rokiem 1300 a 1500, który przyczynił się do rozkwitu elit umysłowych i ich włączenia się w najistotniejsze debaty intelektualne ówczesnego świata chrześcijańskiego na międzynarodowych forach uniwersyteckich i soborowych. Podkreślał on znaczenie Uniwersytetu Praskiego jako centrum intelektualnego „młodszej” Europy do roku 1409 nie tylko w zakresie kształcenia elit, ale również w sferze myśli filozoficznej i teologicznej, inspirującej twórczość naukową w kilku innych środowiskach uniwersyteckich, m.in. wiedeńskim, heidelberskim, krakowskim i lipskim. Zdaniem lubelskiego historyka duże znaczenie dla tej części Europy miał Uniwersytet Wiedeński, w którym studiowało wiele osób z Królestwa Węgierskiego (w latach 1385-1519 blisko 9 tys.). Stanowił on konkurencję najpierw dla uniwersytetu w Pradze, a potem w Krakowie. Dużo miejsca poświęcił J. Kłoczowski Uniwersytetowi Krakowskiemu i jego dokonaniom intelektualnym o charakterze międzynarodowym w dziedzinie sztuk wyzwolonych, filozofii, teologii i prawa. Słusznie zauważył jego rosnące znaczenie, jako jednego z ważnych centrów intelektualnych dla Europy Środkowo-Wschodniej, od czasu soboru w Konstancji do pierwszych dekad XVI w. Studia porównawcze J. Kłoczowskiego obejmowały szeroki kwestionariusz, analizował bowiem główne cechy kultury umysłowej Europy Środkowo-Wschodniej także poprzez średniowieczne księgozbiory z różnych środowisk. Ponadto szerzej omówił elitarne grupy

${ }^{19}$ Idem, Europa centro-orientale. Panorama geografico, cronologico e statistico sulla distribuzione degli Studia degli ordini mendicanti, w: Le scuole degli ordini mendicanti (secoli XIIIXIV), Todi 1978, Convegni del Centro di Studia sulla Spiritualità Medievale, 17, s.127-149; idem, Les ordres mendiants en Europe du Centre-Est et du Nord, w: L'Église et le peuple chrétien dans les pays de l'Europe du Centre-Est et du Nord (XIVe-XVe siècles). Actes du colloque organisé par l'École française de Rome avec la participation de l'Istituto polacco di cultura cristiana (Rome) et du Centre européen de recherches sur les congrégations et ordres religieux (CERCOR). Rome 27-29 janvier 1986, Rome 1990, Collection de l'École Française de Rome, 128, s. 187-200; idem, Dominikanie w środkowo-wschodniej Europie i ich kultura intelektualna oraz pastoralna $w$ wiekach średnich, w: Dominikanie w środkowej Europie w XIII-XV wieku. Aktywność duszpasterska i kultura intelektualna, red. idem, J. A. Spież, Poznań 2002, Studia nad Historią Dominikanów w Polsce, t. 3, s. 153-172; idem, Młodsza Europa, s. 350-354; idem, Wspólnoty chrześcijańskie w tworzacej się Europie, Poznań 2003, s. 435-466; idem, Wspólnoty zakonne w średniowiecznej Polsce, Lublin 2010, s. 317-360. 
humanistów i ich oddziaływanie na dwory monarsze i kręgi możnowładcze na Węgrzech w Polsce i Czechach ${ }^{20}$.

Badania J. Kłoczowskiego nad Europą Środkowo-Wschodnią zmierzały do wszechstronnego ukazania procesów przemian w długim trwaniu $\mathrm{i}$,uchwycenia istoty zjawisk zachodzących w społeczeństwach [- - ] tak w sensie mikrostruktur, jak i makrostruktur aż do organizacji państwowych i ponadpaństwowych" ${ }^{21}$. Wyrażał przy tym przekonanie, że od XIII do XV w. w długim trwaniu ,ukształtowały się trwałe podstawy kultur Polaków, Czechów i Węgrów [--] chrześcijańskich, europejskich i zarazem narodowych, które nie zmieniły się zasadniczo w następnych stuleciach, aż po wiek XX" ${ }^{22}$. W analizach kultury umysłowej w monarchiach Europy Środkowo-Wschodniej wspomniany badacz zastosował rozbudowane modele recepcji i dyfuzji kultury ${ }^{23}$. Akcentował twórcze przejmowanie wzorców i treści kultury intelektualnej oraz ich upowszechnianie w społeczeństwach tej części Europy, kształtowanie i dojrzewanie elit, a następnie ich własny, oryginalny udział w pomnażaniu dorobku intelektualnego łacińskiego świata chrześcijańskiego. Za podstawowe narzędzie pogłębionej europeizacji i dyfuzji łacińskiej kultury umysłowej uważał struktury kościelne z siecią parafialną i klasztorną na czele, które w późnym średniowieczu dysponowały rozbudowanymi systemami szkolnictwa łacińskiego, ośrodkami twórczości pisanej i artystycznej, bibliotekami oraz skryptoriami ${ }^{24}$.

Inspirowane przez J. Kłoczowskiego międzynarodowe konferencje poświęcone problematyce dziejów Europy Środkowo-Wschodniej podejmowały w rozmaitym zakresie sprawy kultury intelektualnej. Na konferencji zatytułowanej „L'Église et le peuple chrétien dans les pays de l'Europe du Centre-Est et du Nord (XIV-XV siècles)", zorganizowanej pod auspicjami École Française de Rome w styczniu 1986 r., pojawiły się zagadnienia dotyczące struktur Kościoła w Europie Środkowo-Wschodniej, formacji duchowieństwa parafialnego i zakonnego oraz środowisk intelektualnych. Francuski mediewista Jacques Verger podsumował dotychczasowe badania nad studiami Polaków, Czechów i Węgrów w uniwersytetach zachod-

${ }^{20}$ Idem, Europa słowiańska, s. 196-237; idem, Młodsza Europa, s. 339-390.

${ }^{21}$ Idem, Młodsza Europa, s. 16.

${ }^{22}$ Ibidem.

${ }^{23}$ Por. H. Manikowska, Społeczne zróżnicowanie zjawisk kultury, w: Historia społeczna późnego średniowiecza. Nowe badania, red. S. Gawlas, Warszawa 2011, s. 141-158; eadem, Wpływ środowiska uniwersyteckiego na kulturę religijna w modelu recepcji kultury, w: Animarum cultura. Studia nad kulturą religijna na ziemiach polskich w średniowieczu, t. 1: Struktury kościelno-publiczne, red. eadem, W. Brojer, Warszawa 2008, s. 444-446.

${ }^{24} \mathrm{~J}$. Kłoczowski, O historię porównawcza, s. 533. 
nioeuropejskich od XIII-XV w. ${ }^{25}$ Po raz pierwszy w historiografii spojrzał on na fenomen peregrynacji po wiedzę uniwersytecką z perspektywy całej Europy Środkowo-Wschodniej. Podkreślił przy tym konieczność pełnej analizy tego zjawiska, bez ograniczania się wyłącznie do ukazywania pojedynczych przykładów wybitnych postaci z Polski, Czech i Węgier, które zdobyły wykształcenie w centrach intelektualnych na Zachodzie. Ponadto J. Verger zaznaczył, że wędrówki studentów do wspomnianych ośrodków dowodzą utrzymywania stałych więzi intelektualnych między poszczególnymi częściami Europy. Z kolei Zenon Kałuża zajął się niezwykle popularnym w środowisku uniwersyteckim praskim i krakowskim komentarzem do Sentencji Piotra Lombarda Utrum Deus gloriosus, który był wykorzystywany jako podręcznik teologii i oddziaływał na kilka pokoleń teologów z Europy Środkowo-Wschodniej ${ }^{26}$.

$\mathrm{Na}$ kongresie Commission Internationale d'Histoire Ecclésiastique Comparée, zorganizowanym w Lublinie we wrześniu 1996 r., głównym tematem było chrześcijaństwo w Europie Środkowo-Wschodniej od narodzin aż do XX w. W opublikowanym po tym kongresie tomie dotyczącym chrześcijaństwa w późnym średniowieczu znalazły się artykuły poświęcone zagadnieniom formacji intelektualnej wyższego duchowieństwa, peregrynacjom osób z Polski, Czech i Węgier na uniwersytety zachodnioeuropejskie w tym okresie oraz obecności duchownych z tej części Europy na dworze papieskim oraz na soborach powszechnych od XIII do XV w., humanistom na polskim i węgierskim dworze Jagiellonów, myśli koncyliarystycznej polskich uczonych i jej powiązaniom z poglądami eklezjologicznymi zachodnich teologów i kanonistów ${ }^{27}$.

W ramach XVII Powszechnego Zjazdu Historyków Polskich w Krakowie we wrześniu 2004 r. odbyło się odrębne sympozjum „Europa Środkowowschodnia od X do XVIII wieku. Jedność czy różnorodność?", moderowane przez J. Kłoczowskiego i Krzysztofa Baczkowskiego ${ }^{28}$. Obok

${ }^{25} \mathrm{~J}$. Verger, Les étudiants slaves et hongrois dans les universités occidentales (XIII ${ }^{e}-\mathrm{XV}^{e}$ siècle), w: L'Église et le peuple chrétien, s. 83-106.

${ }^{26} \mathrm{Z}$. Kałuża, Un manuel de théologie en usage à l'université de Cracovie: le commentaire des Sentences dit Utrum Deus gloriosus, w: L'Église et le peuple chrétien, s. 107-124.

${ }^{27}$ A. Kuźma, Die Ausbildung der Erzbischöfe von Gnesen im Vergleich mit der polnischen Elite Polens im Spätmittelalter (14. und 15. Jh.), w: Christianity in East Central Europe. Late Middle Ages, red. J. Kłoczowski, P. Kras, W. Polak, Lublin 1999, Proceedings of the Commission Internationale d'Histoire Ecclésiastique Comparée, Lublin 1996, cz. 2, s. 117127; J. Verger, Clercs et étudiants d'Europe centrale en Europe occidentale à la fin du Moyen Age, w: L'Église et le peuple chrétien, s. 169-179; U. Borkowska, Humanism at the Court of the Jagellons, w: L'Église et le peuple chrétien, s. 147-156; T. Wünsch, Konziliarismus in Polen - Beispiele für ideellen Transfer von West- nach Osteuropa und die eigenständige Weiterentwicklung im Osten, w: L'Église et le peuple chrétien, s. 137-146.

${ }^{28}$ Europa Środkowowschodnia od X do XVIII wieku - jedność czy różnorodność?, 
kwestii politycznych, ustrojowo-prawnych, gospodarczych, religijnych tego regionu Europy w średniowieczu i dobie nowożytnej został podjęty problem elit intelektualnych oraz ich dorobku naukowego (przede wszystkim filozoficznego i teologicznego) w późnośredniowiecznej Polsce, Czechach i na Węgrzech w aspekcie porównawczym ${ }^{29}$. Zauważone zostały istotne cechy wspólne w refleksji intelektualnej i metodach uprawiania nauki w ówczesnych środowiskach uniwersyteckich stanowiących centra umysłowe regionu (Praga, Wiedeń, Kraków).

$Z$ kolei na międzynarodowej konferencji „Religious Space of East-Central Europe: Open to the East and the West", zorganizowanej z inicjatywy J. Kłoczowskiego przez Commission Internationale d'Histoire et d'Étude du Christianisme (CIHEC) w Lublinie i Lwowie we wrześniu 2007 r., problematyka elit intelektualnych w Europie Środkowo-Wschodniej w wiekach średnich nie była poruszana $w$ ramach odrębnej sesji ${ }^{30}$. Została ona $\mathrm{w}$ pewnym zakresie uwzględniona $\mathrm{w}$ ramach sesji dotyczącej kaznodziejstwa jako instrumentu ewangelizacji, na której Krzysztof Bracha podsumował stan badań nad kaznodziejstwem średniowiecznym w Europie Środkowo-Wschodniej i określił perspektywy badawcze w tej sferze ${ }^{31}$. W swoich wywodach skupił się na dokonaniach polskich, czeskich, węgierskich i słowackich mediewistów w zakresie edycji zabytków kaznodziejstwa oraz studiów nad kolekcjami kazań, które powstały w średniowiecznej Polsce, Czechach i na Węgrzech. Natomiast Zdeněk Uhlír, András Németh, Stanislava Kuzmová, Alicja Szulc i Anna Zajchowska zajęli się analizą kilku szczegółowych kwestii, głównie o charakterze źródłoznawczym, w tym technikami redagowania, kompilowania i kopiowania kazań i całych ko-

red. K. Baczkowski, J. Smołucha, Kraków 2005. Wystąpienia Stanisława Byliny, Krzysztofa Ożoga, Antoniego Podrazy i Wacława Uruszczaka z tego sympozjum ukazały się również w językach angielskim lub francuskim w tomie: Europe Centrale entre l'Est et l'Ouest. Central Europe between East and West, red. J. Kłoczowski, współpr. I. Goral, H. Łaszkiewicz, Lublin 2005.

${ }^{29}$ K. Ożóg, Elity intelektualne krajów Europy Środkowowschodniej w późnym średniowieczu $i$ ich horyzonty myślowe, w: Europa Środkowowschodnia od X do XVIII wieku, s. 135-149; F. Uličný, Elita intelektualna na Słowacji $w$ XV wieku, w: Europa Środkowowschodnia od X do XVIII wieku, s. 151-155. Dorobek elity umysłowej w Wielkim Księstwie Litewskim od chrystianizacji do upadku Rzeczypospolitej został scharakteryzowany syntetycznie na wspomnianym sympozjum przez Marię B. Topolską (Dziedzictwo kultury zachodnioeuropejskiej w Wielkim Księstwie Litewskim i na ziemiach ruskich Korony od XV do XVIII wieku, w: Europa Środkowowschodnia od X do XVIII wieku, s. 195-214).

30 Zob. K. Bracha, P. Kras, Wstęp, w: Przestrzeń religijna Europy Środkowo-Wschodniej $w$ średniowieczu. Religious Space of East-Central Europe in the Middle Ages, red. iidem, Warszawa 2010, s. 13-15.

${ }^{31}$ K. Bracha, Średniowieczne kaznodziejstwo w Europie Środkowo-Wschodniej. Stan i perspektywy badawcze, w: Przestrzeń religijna, s. 201-210. 
lekcji na wybranych przykładach z Europy Środkowo-Wschodniej, a także przekazem treści ewangelizacyjnych w kazaniach, kaznodziejską dydaktyką moralną i niektórymi wątkami ideowymi w kazaniach o świętych ${ }^{32}$.

Natomiast na międzynarodowej konferencji w Warszawie w listopadzie 2008 r.pt. „Polska i Europa Środkowo-Wschodnia we wspólnocie europejskiej", animowanej przez J. Kłoczowskiego, w sesji dotyczącej średniowiecza zagadnienie kultury umysłowej jako istotnego czynnika kształtującego obraz Europy Środkowo-Wschodniej w tym okresie nie pojawiło się na szerszą skalę w wystąpieniach badaczy ${ }^{33}$. Sporo było w nich mowy o recepcji rozmaitych zachodnioeuropejskich wzorców kulturowych w Czechach, Polsce i na Węgrzech XI-XV w., ale poza nawiasem rozważań pozostały kształtujące się środowiska intelektualne i szkolnictwo ${ }^{34}$.

Nurt badań nad kulturą umysłową Europy Środkowo-Wschodniej rozwinięty przez J. Kłoczowskiego jest kontynuowany w kilku ośrodkach mediewistycznych. Przede wszystkim należy podkreślić porównawcze studia nad kulturą pisma w średniowiecznej Polsce, Czechach i na Węgrzech prowadzone od kilkunastu lat przez Annę Adamską w Utrechcie. W odniesieniu do obszaru zainteresowań nawiązuje ona bezpośrednio do koncepcji Europy Środkowo-Wschodniej J. Kłoczowskiego, pod tym bowiem pojęciem („East Central Europe”, „Central Europe”) umieszcza średniowieczną Polskę, Czechy i Węgry ${ }^{35}$. Najpierw nakreśliła ona program studiów odwołujący się do osiągnięć współczesnej mediewistyki, która intensywnie bada: ,zasięg społeczny średniowiecznej kultury pisma i jej wzajemne relacje z kulturą żywego słowa (oralnością), jak również problemy szczegółowe

${ }^{32}$ Z. Uhlír, Středověké kazatelské sbírky a jejich místo v procesu kázání, w: Przestrzeń religijna, s. 211-219; A. Németh, Teaching, Learning and Preaching in Fifteenth-century Rhyming Decalogue, w: Przestrzeń religijna, s. 221-233; S. Kuzmová, An Exemplary Sheferd: Thema „Ego sum pastor bonus" and Sermons on Saint Stanislaus of Kraków in the Later Middle Ages, w: Przestrzeń religijna, s. 235-255; A. Szulc, Kaznodziejstwo bernardyńskie w misji duszpasterskiej Kościoła polskiego w okresie późnego średniowiecza, w: Przestrzeń religijna, s. 271-280; A. Zajchowska, Quadruplex est modus faciendi librum. Kazania ad clerum z rękopisu I Q 377 Biblioteki Uniwersytetu Wrocławskiego w świetle średniowiecznej teorii autorstwa, w: Przestrzeń religijna, s. 281-306.

${ }^{33}$ Materiały z tej konferencji zostały opublikowane w tomie: East-Central Europe in European History. Themes and Debates, red. J. Kłoczowski, H. Łaszkiewicz, Lublin 2009 (zob.s. 87-203: rozdz. 2: „Middle Ages - the Formative Centuries”).

${ }^{34}$ Zob. przede wszystkim: A. Vauchez, La christianisation comme éléments d'intégration des pays de l'Europe du Centre-Est à la „Vieille Europe” (IX $-X V^{e}$ siècles), w: East-Central Europe in European History, s. 97-108; G. Klaniczay, Une Europe centrale au Moyen Age? Réflexions historiographiques et recherches sur l'histoire croisée, w: East-Central Europe in European History, s. 109-130.

${ }^{35}$ A. Adamska, The Introduction of Writing in Central Europe (Poland, Hungary and Bohemia), w: New Approaches to Medieval Communication, red. M. Mostert, wstęp M. Clanchy, Turnhout 1999, s. 165-169. 
dotyczące dziejów książki rękopiśmiennej i dokumentu, funkcjonowania średniowiecznych bibliotek i kancelarii" ${ }^{36}$, a także różne formy i sposoby obcowania z tekstem pisanym (lektura), związki między pismem a religią, rolę pisma w sprawowaniu władzy, przede wszystkim w zarządzaniu i administrowaniu państwem oraz zagadnienie narodzin mentalności kształtowanej przez pismo u schyłku wieków średnich w wyniku postępów alfabetyzacji społeczeństw i praktyczne wykorzystanie pisma do komunikacji i memoryzacji. A. Adamska podniosła, że „ujawnienie mechanizmów rozwoju kultury pisma w Czechach, Polsce i na Węgrzech może lepiej naświetlić relacje między głównymi ośrodkami kulturalnymi średniowiecznej Europy a jej peryferiami" ${ }^{37}$. Wyróżniła ona trzy fazy w rozwoju kultury pisma w Europie Środkowo-Wschodniej ${ }^{38}$. Pierwszy okres (XI-XII w.) związany z wprowadzeniem pisma po przyjęciu chrześcijaństwa przez Czechy, Polskę i Węgry, drugi przypada na XIII-XIV w., wówczas bowiem nastąpił poważny wzrost roli pisma w życiu społecznym i politycznym, ostatni zaś, obejmujący XV stulecie, to czas, w którym pismo staje się powszechnym narzędziem komunikacji społecznej i Europa Środkowo-Wschodnia aktywnie uczestniczy w europejskiej wymianie kulturalnej. Szerszej analizy porównawczej wspomniana badaczka dokonała w odniesieniu tylko do pierwszej fazy, ukazując proces wprowadzania pisma do wymienionych trzech krajów przez Kościół, używający słowa pisanego w liturgii, działalności duszpasterskiej i prawie, a także przez monarchie, gdyż władcy organizują kancelarie wystawiające dokumenty, głównie dla instytucji kościelnych ${ }^{39}$. Podkreśliła, że Przemyślidzi, Piastowie i Arpadowie fundowali wówczas dla zakładanych przez siebie kościołów kosztowne rękopisy liturgiczne, które - podobnie jak w zachodniej Europie - stały się instrumentem propagandy monarszej i podkreślały ich związek z Bogiem oraz sakralny charakter władzy. Ponadto A. Adamska komparatystycznie omówiła łacińską twórczość hagiograficzną, historiograficzną i dewocyjną (modlitwy oraz pieśni) z XI-XII w. w Polsce, Czechach i na Węgrzech, a następnie skromne ślady twórczości w językach wernakularnych oraz kształtujące się ośrodki twórczości intelektualnej przy katedrach biskupich i kancelariach monarszych. Zasygnalizowała również formy kontaktu z pismem społeczeństw z Europy Środkowo-

${ }^{36}$ A. Adamska, Średniowiecze na nowo odczytane. O badaniach nad kultura pisma, RH 65, 1999, s. 129.

37 Ibidem, s. 153.

${ }^{38}$ Eadem, The Introduction of Writing in Central Europe, s. 168-169.

${ }^{39}$ Ibidem, s. 174-187. 
-Wschodniej, w których dominowali illiterati. Odrębnie zbadała tę ostatnią kwestię w odniesieniu do władców środkowoeuropejskich ${ }^{40}$.

W ramach sformułowanego programu komparatystycznych badań nad kulturą pisma w średniowiecznych Czechach, Polsce i na Węgrzech została zorganizowana w Utrechcie przez A. Adamską i Marco Mosterta duża konferencja międzynarodowa zatytułowana „The Development of Literate Mentalities in East Central Europe" (28-30 VI 2001). Jej efekty ukazały się drukiem w $2004 \mathrm{r}$. w obszernym tomie pod takim samym tytułem, zawierającym 28 studiów pióra mediewistów europejskich i amerykańskich ${ }^{41}$. Ich uwaga skupiała się na problematyce recepcji pisma w życiu społeczeństw tej części Europy, wykształconych i analfabetach (literati illiterati), intelektualnej roli krakowskiego środowiska uniwersyteckiego, a także na kwestiach dotyczących wielojęzyczności i twórczości w językach wernakularnych, śladów tradycji oralnej, funkcji rytuału w komunikacji społecznej i politycznej oraz związków pisma z obrazami i folklorem. Omawiany tom stanowi istotny krok w badaniach szczegółowych nad drogami kształtowania się piśmienności i mentalności społecznej z nią związanej w Europie Środkowo-Wschodniej i przyczyni się bez wątpienia do pogłębienia studiów komparatystycznych nad rozwojem średniowiecznej kultury umysłowej w Polsce, Czechach i na Węgrzech.

Przekonanie o rozległych perspektywach badań nad dziejami Europy Środkowo-Wschodniej zakorzeniło się mocno w historiografii polskiej i węgierskiej, a nieco w mniejszym stopniu w czeskiej. Świadczą o tym publikowane prace indywidualne i zespołowe oraz międzynarodowe konferencje i sympozja organizowane w tych krajach. Mają one bardzo zróżnicowany charakter - niektóre realizują w istotnym zakresie badania komparatystyczne lub dostarczają materiału analitycznego do tego rodzaju studiów, a niekiedy używana w tytule konferencji formuła Europy Środkowej lub Europy Środkowo-Wschodniej ma na celu tylko przybliżenie geograficzno-historycznego kontekstu omawianych zagadnień. Problematyka szeroko pojętej kultury umysłowej jest w nich obecna na dalszym planie, często poruszana marginalnie ${ }^{42}$.

${ }^{40}$ Eadem, „Audire, intelligere, memorie commendare”. Attitudes of the Rulers of Medieval Central Europe towards Written Texts, w: Along the Oral-Written Continuum. Types of Texts, Relations and their Implications, red. S. Ranković et al., Turnhout 2010, s. 337-357.

${ }^{41}$ The Development of Literate Mentalities in East Central Europe, red. A. Adamska, M. Mostert, Turnhout 2004.

${ }^{42}$ Wymienię tylko niektóre: Modernizacja struktur władzy w warunkach opóźnienia. Europa Środkowa i Wschodnia na przełomie średniowiecza i czasów nowożytnych, red. M. Dygo, S. Gawlas, H. Grala, Warszawa 1999; Stosunki wyznaniowe w Europie Środkowej i Wschodniej w XIV-XVII wieku, red. M. Dygo, S. Gawlas, H. Grala, Warszawa 2002; Ostmitteleuropa im 14.-17. Jahrhundert - eine Region oder Region der Regionen?, red. M. Dygo, S. Gawlas, 
Historiografia niemiecka we współpracy z badaczami z Polski, Czech i Węgier podejmuje niektóre tematy dotyczące dziejów Europy Środkowo-Wschodniej, w tym również związane z kulturą intelektualnąa ${ }^{43}$. Istotne znaczenie miały w tym zakresie międzynarodowe konferencje zorganizowane przez Institut für ostdeutschen Kirchen- und Kulturgeschichte Ostdeutschlands: „Humanismus und Renaissance in Ostmitteleuropa vor der Reformation” (Ratyzbona, lipiec 1992 r.) i „Kirchliche Reformimpulse des 14./15. Jahrhunderts in Ostmitteleuropa" (Magdeburg, lipiec/sierpień 2001 r.), a także przez Niemiecki Instytut Historyczny w Warszawie: „Die «Blüte» der Staaten des östlichen Europa im 14. Jahrhundert” (październik 1999 r.). Szczególnie pierwsza z nich ukazała drogi recepcji humanizmu w Europie Środkowo-Wschodniej (rozumianej przez organizatorów Winfrieda Eberharda i Alfreda A. Strnada jako obszar obejmujący królestwa Czech, Węgier i Polski), a następnie szeroką panoramę ośrodków humanizmu i ich dokonań w tej części Europy ${ }^{44}$. Z kolei druga konferencja skupiła się na dążeniach reformatorskich i przeprowadzanych reformach w Kościele na terenie Europy Środkowo-Wschodniej, głównie w monarchiach czeskiej, węgierskiej i polskiej ${ }^{45}$. Mimo że przeważała na niej problematyka czeska, to jednak kilku badaczy w swych wystąpieniach omawiało inne środowiska reformatorskie - Thomas Wünsch scharakteryzował program reform sformułowany i realizowany przez wybitnego prawnika biskupa Piotra Wysza w diecezji krakowskiej w latach 1392-1412, a A. A. Strnad omówił działalność biskupów-humanistów na Śląsku, Morawach i Węgrzech w drugiej połowie XV i na początku XVI w. oraz ich troskę o kształcenie młodzieży według modelu humani-

H. Grala, Warszawa 2003; Metropolie Europy Środkowo-Wschodniej w XV i XVI wieku, red. L. Belzyt, J. Pirożyński, Kraków 2000; Political Culture in Central Europe $\left(10^{\text {th }}-20^{\text {th }}\right)$, cz. 1: Middle Ages and Early Modern Era, red. H. Manikowska, J. Pánek, współpr. M. Holý, Prague 2005; Rituály, ceremonie a festivity ve střední Evropě 14. a 15. století, red. M. Nodl, F. Šmahel, Praha 2009; Lux Romana w Europie Środkowej ze szczególnym uwzględnieniem Śląska, red. A. Barciak, Katowice 2001; Źródła kultury umysłowej w Europie Środkowej ze szczególnym uwzględnieniem Górnego Śląska, red. A. Barciak, Katowice 2005; Kultura prawna w Europie Środkowej, red. A. Barciak, Katowice 2006; G. Klaniczay, Holy Rulers and Blessed Princesses. Dynastic Cults in Medieval Central Europe, Cambridge 2002; M. Font, Spannungsfeld der christlichen Grossmächte. Mittel- und Osteuropa im 10.-12. Jahrhundert, Herne 2008; K. Baczkowski, Polska i jej sasiedzi za Jagiellonów, Kraków 2012.

${ }^{43}$ Zob. E. Mühle, East Central Europe in Historiographic Concepts of German Historical Studies, w: East-Central Europe in European History, s. 55-72.

${ }^{44}$ Humanismus und Renaissance in Ostmitteleuropa vor der Reformation, red. W. Eberhard, A. A. Strnad, Köln 1996, Forschungen und Quellen zur Kirchen- und Kulturgeschichte Ostdeutschland, 28.

${ }^{45}$ Kirchliche Reformimpulse des 14./15. Jahrhunderts in Ostmitteleuropa, red. W. Eberhard, F. Machilek, Köln-Weimar-Wien 2006, Forschungen und Quellen zur Kirchen- und Kulturgeschichte Ostdeutschlands, 36. 
stycznego ${ }^{46}$. Na trzeciej konferencji w ramach analiz porównawczych polityki, struktur wewnętrznych, procesów modernizacyjnych i funkcjonowania monarchii Europy Środkowo-Wschodniej i Wschodniej Krzysztof Ożóg ukazał komparatystycznie służbę osób z wykształceniem uniwersyteckim w monarchiach czeskiej, polskiej i węgierskiej w XIV w. i ich rolę w instytucjach centralnych (dwór, kancelaria, rada królewska, skarb), dyplomacji i tworzeniu oficjalnej państwowej historiografii ${ }^{47}$.

Badaniem dziejów Europy Środkowo-Wschodniej programowo zajmuje się od 1995 r. Geisteswissenschaftliches Zentrum für Geschichte und Kultur Ostmitteleuropas przy uniwersytecie w Lipsku. We współpracy z polskimi, czeskimi i węgierskimi uczonymi instytucja ta organizuje międzynarodowe konferencje oraz koordynuje projekty badawcze, które skupiają się przede wszystkim na interdyscyplinarnych studiach nad sztuką, religią i kulturą w państwach znajdujących się pod władzą dynastii Jagiellonów od XIV do XVI w. Przedmiotem zainteresowania są również elity intelektualne związane z dworami Jagiellonów, ich działalność i dokonania, a także formacja umysłowa, mecenat i fundacje poszczególnych członków tej dynastii ${ }^{48}$.

Na XVIII Powszechnym Zjeździe Historyków Polskich w Olsztynie we wrześniu 2009 r. K. Ożóg zorganizował interdyscyplinarny panel dyskusyjny pt. „Średniowieczne korzenie nauki i środowisk uniwersyteckich w Europie środkowej i środkowo-wschodniej", w którym uczestniczyli historycy, historycy filozofii, teologii i nauki: Elżbieta Jung, Mikołaj Olszewski, Jacek Soszyński, Dagmara Wójcik, Maciej Zdanek i Włodzimierz Zega. Jego głównym celem była dyskusja w gronie mediewistów nad kształtowaniem się środowisk intelektualnych w Europie Środkowej i Środkowo-Wschodniej (obejmujących Rzeszę Niemiecką oraz królestwa Czech, Polski i Węgier) w okresie średniowiecza i ich dorobkiem naukowym ${ }^{49}$. Uczestnicy debaty wskazywali na charakterystyczne cechy

${ }^{46}$ T. Wünsch, Das Reformprogramm des Krakauer Bischofs Petrus Wysz 1392-1412. Mit Neuedition der 22-Punkte-Liste „De reformatione ecclesie”, w: Kirchliche Reformimpulse, s.157-178; A. A. Strnad, Die Erneuerung von Bildung und Erziehung durch die Humanisten-Bischöfe in Schlesien, Mähren und Ungarn, w: Kirchliche Reformimpulse, s. 179-215.

${ }^{47}$ K. Ożóg, Intellektuelle im Dienst der Staaten Ostmitteleuropas. Vergleichende Betrachtungen, w: Die „Blüte” der Staaten des östlichen Europa im 14. Jahrhundert, s. 229-255.

${ }^{48}$ Zob. Metropolien im Wandel. Zentralität in Ostmitteleuropa an der Wende vom Mittelalter zur Neuzeit, red. E. Engel, K. Lambrecht, H. Nogossek, Berlin 1996; Die Länder der böhmischen Krone und ihre Nachbarn zur Zeit der Jagiellonenkönige (1471-1526). Kunst, Kultur, Geschichte, red. E. Wetter, Ostfildern 2005, Studia Jagellonica Lipsiensia, 2; Hofkultur der Jagiellonendynastie und verwandter Fürstenhäuser. The Culture of the Jagiellonian and Related Courts, red. U. Borkowska, M. Hörsch, Ostfildern 2010, Studia Jagellonica Lipsiensia, 6.

${ }^{49}$ Zob. T. Gajownik, Panel dyskusyjny: Średniowieczne korzenie nauki i środowisk uniwersyteckich $w$ Europie środkowej i środkowowschodniej, w: Powrót do źródeł. Pamiętnik XVIII Powszechnego Zjazdu Historyków Polskich w Olsztynie 16-19 września 2009 roku, 
uprawiania sztuk wyzwolonych, filozofii, teologii oraz prawa, które odróżniały wspomniane środowiska uniwersyteckie od zachodnioeuropejskich. Podkreślali przede wszystkim zróżnicowanie doktrynalne i dogodne warunki dla rozwoju filozofii przyrody, filozofii moralnej, astronomii, logiki i teologii. Ich zdaniem nowatorskie dokonania uczonych ze Środkowej i Środkowo-Wschodniej Europy były często związane z wyjściem poza schemat scholastycznej uprawy nauki, czego znakomitym przykładem była twórczość Mateusza z Krakowa i Jakuba z Paradyża.

Szereg kwestii dotyczących specyfiki środowisk uniwersyteckich w Europie Środkowej i Środkowo-Wschodniej z olsztyńskiej dyskusji panelowej zostało podjętych na międzynarodowej konferencji "What is New in the New Universities? Learning in Central Europe in Later Middle Ages (13481500)", zorganizowanej w Łodzi we wrześniu 2011 r. przez Société Internationale pour l'Étude de la Philosophie Médiévale. Mediewiści z całego świata prezentowali wyniki szczegółowych badań nad nurtami doktrynalnymi rozwijającymi się w uniwersytetach środkowoeuropejskich, komentarzami oraz koncepcjami filozoficznymi i teologicznymi, które zrodziły się w tych środowiskach, oraz osiągnięciami uczonych z krakowskiej i wiedeńskiej szkoły astronomicznej. Dokonania intelektualne mistrzów z uniwersytetów środkowej Europy były prezentowane w kontekście zachodnioeuropejskim, co umożliwiało określenie ich twórczego wkładu w rozwój filozofii, teologii i astronomii ${ }^{50}$.

Z omówionych powyżej badań wynika, że koncepcja studiów nad kulturą umysłową Europy Środkowo-Wschodniej (Środkowej) w średniowieczu zadomowiła się na dobre w mediewistyce światowej. Rozszerza się również jej zakres tematyczny, gdyż badaczy interesują nie tylko generalne procesy wpływające na specyfikę tej części Europy w dziedzinie życia intelektualnego, ale także konkretne jego przejawy oraz osiągnięcia, które konstytuowały odrębności, a równocześnie przyczyniały się do rozwoju i bogactwa intelektualnego świata łacińskiego. Koncept badań komparatystycznych nad środowiskami intelektualnymi Europy Środkowo-Wschodniej jest podejmowany coraz intensywniej przez mediewistów różnych specjalności i sięga wielu poziomów kultury umysłowej, a także daleki jest od wyczerpania ${ }^{51}$. Należy jednak zauważyć, że omawianemu nurtowi badań nie towarzyszy bardziej pogłębiona refleksja teoretyczna

red.J. Gancewski, N. Kasparek, A. Korytko, Olsztyn 2010, s. 177-179 (sprawozdanie z obrad). Pełny zapis tej dyskusji nie został wydany drukiem.

${ }^{50}$ Materiały z tej konferencji są w druku. Por.K. Ożóg, The Role of Poland in the Intellectual Development of Europe in the Middle Ages, Kraków 2009.

${ }^{51}$ Por. A. Adamska, Czy potrzebna nam jest społeczna historia języka?, w: Historia społeczna późnego średniowiecza, s. 197-201. 
i metodologiczna ${ }^{52}$. Generalnie mediewiści stoją na gruncie koncepcji badań komparatystycznych nakreślonych przez J. Kłoczowskiego z zastosowaniem rozbudowanych modeli recepcji i dyfuzji kultury.

\section{Remarks on Research into Mediaeval Intellectual Culture in East-Central Europe}

The discussion on the concept of East-Central Europe conducted in historical writings for several past decades favoured the development of studies focused on this part of Europe as well as its mediaeval intellectual culture. The presented article discusses the trends of assorted investigations and their heretofore outcome. An opinion well ensconced in historiography claims that during the Middle Ages East-Central Europe was composed of three monarchies: Polish (together with Lithuania after the latter's acceptance of Christianity), Bohemian, and Hungarian as well as the Teutonic Order state on the Baltic. The concept of East-Central Europe (or Central Europe) in research dealing with intellectual culture was first introduced by Adam Vetulani and Ferdinand Seibt, and subsequently was considerably modified and expanded by Jerzy Kłoczowski. The Lublin-based historian created not only an extensive questionnaire for comparative research relating to East-Central Europe but his works presented analyses concerned with the chief elements of intellectual culture, including schools (parish, chapter and monastic) in Bohemia, Poland, and Hungary, universities and the academic education of representatives of those monarchies and intellectual elites, their role and accomplishments. Such studies are continued and progress in several centres, i.a. in Utrecht by Anna Adamska, who delves into the mediaeval culture of writing in East-Central Europe. The concept of comparative research into the titular issue in this particular part of Europe has been increasingly intensively pursued by mediaevalists representing assorted specialist domains and reaches ever deeper strata of such culture. The researchers in question successfully apply expanded models of the reception and diffusion of culture.

Translated by Aleksandra Rodzińska-Chojnowska

${ }^{52}$ Por. H. Manikowska, Społeczne zróżnicowanie zjawisk kultury, s. 141-158. 